
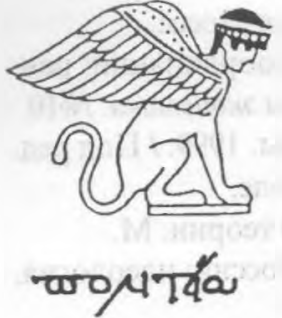

1 Подробнее с.м Делюсин Л.П. Борьба вокруг идейпого наследия Сунь Ятсеиа. - Обиественнополитическая мысль в Kuтае (конеи $X I X-$ narano $\left.X X{ }_{8 .}\right)-M$ : "Наука», 1988. C. 199-242.

${ }^{2}$ Подробнее см., иапример: Решетов A.M. Kumaǔub! (хань) в свете теории этноса. XXVIII научная конферениия "Обчество и государство в

Kumae». Тезисы и доклады. Часть II. M. Ииституm востоковедения PAH. 1998. - C. 265-270.

\section{КИТАЙ: ВОЗРОЖДЕНИЕ НАЦИОНАЛЬНОЙ ИДЕИ}

Размышления о национальной идее китайцев скорее всего требуют использования каких-то особых слов или даже понятий, так как в данном случае речь идет о народе и стране, имеющих самую древнюю письменную историю, философию, литературу, даже самые древние таблицы предков. Это страна, в которой как нигде более судьбы отдельных семей документально неразрывно связаны с историей родного края. Конечно, сохранение до наших дней прямых потомков великого философа Конфуция - явление, возможно, уникальное даже в условиях Китая. Фактом, однако, является то, что десятки миллионов китайцев, на протяжении многих поколений живущие за пределами родных мест, знают родину предков, чтят могилы и берегут родовые кумирни, почитая за долг ежегодно приезжать на родину, чтобы встретить новую весну в кругу близких.

Давно отмечено, что повсеместно основу китайского общества составляют семья и род (клан), но не личность. Распространена точка зрения, согласно которой из-за слабого развития материальной культуры семья и род (клан) не развились до такой степени, чтобы стать основой организации государства или нации. В концепции «трех народных принципов»' Сунь Ятсена, национализм является центральным звеном, потому что с его помощью легче всего сделать нацию основой государства. Предполагалось, что дух нации создать в Китае гораздо легче, чем на Западе, так как там между индивидуумом и государством лежит пустота, а в Китае - род (клан).

При всём этом приходится иметь в виду широко распространенные представления о существовании единой китайской нации. Трудно признать китайцев (хань цзу) сформировавшимся, единым этносом. Современная наука выцеляет в китайском языке до десяти групп диалектов, между которыми различия существуют не только на уровне фонетики, но также в лексике и даже в грамматике. Официальный язык, провозглашенный общепринятым (гоюй, путунхуа), распространяемый всей мощью государства на протяжении XX в., далеко не в полной мере выполняет функции основного средства общения всех локальных групп китайцев. На наиболее крупных диалектах не прекращаются попытки создания художественной литературы, функционируют разные жанры китайского театра, работает кинематограф, радио, телевидение. Диалекты являются средством общения в семье ?

Существование китайской цивилизации с её региональными вариантами не вызывает сомнения. Определяющее влияние на её формирование всегда оказывали такие факторы, как длительное непрерыв- 
ное сушествование китайской государственности, распространенные государством единые ритуалы, нормы и нормативы жизни, китайская иероглифическая письменность и созданная на её основе письменная традиция, конфуцианская идеология. Конфуцианство, смешиваясь с даосизмом, пронизало распространенные в Китае буддизм, ислам и христианство. В результате в границах отдельных регионов сформировались локальные (этнические и этнографические) группы, обладающие определенным сознанием своего единства и отличающие себя от других групп по языку, культуре, самосознанию, самоназванию, уровню социально-экономического развития, условиям экономической жизни и экономическим интересам. За неимением других понятий приходится пользоваться термином «группы», но надо непременно помнить, что иные из них по своей численности достигают 100 и более миллионов человек.

В столь специфических исторических условиях государство могло существовать и действительно существовало, руководствуясь своими особыми идеологией, институтами, нормами, ритуалами. После создания первого единого государства его главным идеологическим постулатом выступало великодержавие, основанное на убеждении, что Китай является центром вселенной, центром истории, центром народов.

Правящая династия Цинов (монголов) не смогла уберечь страну от посягательств империалистических государств. С середины XIX века многие поколения китайских патриотов жаждали нацнонального освобождения и возрождения независимости государства. С тех пор прошло более 150 лет, но и теперь воспоминания о тех временах наполняют горечью мысли современников. Маомао, дочь Дэн Сяопина, пишет: «Необъятное по территории великое восточное государство, знаменитое сановное правительство династии Цин, в прошлом никогда не подвергались такому страшному испытанию, оскорблению и позору. Более того, и другие западные государства, вступив

Маомао. Мой отеи Дэн Сяопин. (пер. с китайского). - $M$.: РУССЛИТ, 1995. C. 42 .

' Там же. C. 45. вслед за Англией на проторенный ею путь, одно за другим ринулись в Китай» ${ }^{3}$. Она убеждена: «Россия, расположенная вдоль северной границы Китая, уже давно словно тигр, присматривалась к его территории. В 1858 г. был подписан китайско-российский «Айгуньский», В 1860 г. - «Пекинский», а в 1881 г. - «Илийский» договоры и другие неравноправные соглашения, по которым к России отошли территория северо-восточной части страны более чем в один миллион кв. км, расположенная к северу от реки Хэйлунцзян $(A м y p-B . \Gamma$.) и к востоку от реки Усулицзян (Усури - В.Г.), а также район северо-западного Китая более чем в 500 тыс. кв. км, лежащий к востоку и к югу от озера Балхаш. Кроме того, в 1895 г. царская Россия под видом аренды закрепилась в двух важных портах Ляодунского полуострова - Люйшунь и Далянь (Порт-Артур и Дальний - В.Г.) »4. И ещё: «Россия и Япония отхватили часть лакомого пирога, но и другие старались от них не 
${ }^{5}$ маомао. Мой отец Дэи Сяопии. (nер. с китайского), - $M$.. РУССЛИТ, 1995. -

C. 46 .

отстать. В результате в 1895-1900 гг. Китай, страна с четырехтысячелетней древней культурой, стоял перед угрозой гибели своей государственностин ${ }^{5}$.

Мысли и чувства множества патриотов были направлены на освобождение своей страны. Потребовались, однако, несколько десятилетий, прежде чем постепенно выкристаллизовались идеи освобождения, равно как представления о желанном обществе и государстве. Не сразу стало ясно, что для освобождения необходима революция, десятилетия патриоты спорили о том, что важнее - политическая или национальная революция. В силу специфики того времени борьба за политическое и национальное освобождение в конечном счёте слились.

Победа во Второй мировой войне, а затем - в революции в 1949 г. были восприняты в стране как закономерный итог долгой и кровавой борьбы. Китайский народ воспрянул: китайский народ никогда более не станет на колени. Компартия вместе с согозниками по национально-освободительной борьбе взялась за строительство социализма. Социально-политические ориентиры на десятилетия как будто оттеснили на второй план национальную идею, на протяжении 100 лет питавшую народ своими живительными соками.

С началом периода реформ и открытости в конце 1970-х годов ситуация изменилась. Идея социализма за 1958-1977 гг., то есть за годы «большого скачка» и «культурной революции», оказалась совершенно девальвированной. Десятками миллионов жертв китайский народ заплатил за «строительство социализма» в те времена, ставшие периодом национальной трагедии, расстройства экономики и обнищания народа. Не случайно лозунг Дэн Сяопина «Смотреть вперед!» (Сян цянь кань), выдвинутый им сразу же после «культурной революции», огромной массой китайцев был немедленно интерпретирован совсем иначе: «Смотреть на деньги!» Благо по звучанию они были совершенно одинаковы. Разочарование в социализме было полным.

Успехи первого десятилетия реформ, несмотря на немалые проблемы, породили в народе огромные надежды, но в 1990-е годы обострение социальной обстановки вызвало их крах. Сохранение нишеты огромных масс, особенно крестьянства, резкая поляризация доходов, безработица, всепроникаюшая коррупция - эти и другие явления оказали огромное воздействие на все слои населения. «Третьему поколению руководителей», видимо, становилось с каждым годом всё более ясно, что призыв Дэн Сяопина к строительству «социализма китайского образца» катастрофически быстро терял смысл и привлекательность в глазах и умах населения. Недаром появился нешуточный лозунг: «Социалистическими методами строить капитализм китайского образца!»

Началось постепенное восстановление старой, проверенной временем, традициями и политически стройной национальной идеи - «великого возрождения нации Китая» (чжунхуа миньцзу). На XIII съезде (1987), официально оформившем концепцию «начального этапа соци- 
\$ Докуниенив XIII Всекитайского съезда Кониунистической партии Kumaя (25 октября - I ноября 1987 20da).Пекин: Издательство питераптуры на иіостранных языkax, 1988. - C. 14

Zhongguo gungchandag di shiu ci quinguo daibiaodahoi wenjian hoipian (Сборнuк докунентов $X V \mathrm{Bce}$ кипиайского съезда Коммулистической nаріми Киmaя). C. 16 .

' Tan же, C. 46

- Jing Jemin. Qianmian jianshe riaokang shehoi, kaichian shongguo tesi shehoizhui shie xin juyimian - jai Zhongguo gungchandag di shilu ci quinguo daibiaodahoi shang de baogao (I Цзэлинь. Kонплекс no cmpoumb oбще ство средней зажсимочности, созда6аmb Hogylo обстановку в деле сочиализна китайскux ocoбeнносnейдокпад на XVI Bceкитайском съезде Комнуиистической nартии Китая). -

Beijing: Renmin chubanshe, 2002. E $1-2$.

10 Tan же, $C$. 69 10. $14,18 u \partial p$

"Lum no: Kpulnoв A $\Gamma$. Oбuecmвenthaя wblc.7b и иоеологическая борь

6а в Kumae 1900 1917 22.) - M.: «Haука», 1972. - C. 232

12 Taи же.

${ }^{13}$ bonee noдробно cм.: Mockates A.A. ализма» как предстоящего 100-летнего периода материально-технического, экономического, культурного и политического строительства «полного» социализма, было сказано, что одновременно это будет «период великого возрождения китайской нации, осуществляемого настойчивыми усилиями всего народа) ${ }^{6}$. В докладе ЦК XV съезду (1997) появилась принципиально новая формулировка: «начальный этап социализма» определялся, в частности, как «исторический этап осуществления великого возрождения нации Китая на основе социализма» ${ }^{7}$. Иными словами, социализм был превращен в средство «великого возрождения нации Китая». Объявлено, что вся предшествующая деятельность партии и многочисленные жертвы служили «великому возрождению нации Китая» ${ }^{8}$. Восстановление суверенитета КНР над Сянганом (Гонконгом) и Аомэнем (Макао) провозглашены победой не социализма, а «великого возрождения нации Китая». Нa XVI съезде (2002) уточнено: «великое возрождение нации Китая на путях социализма китайского образца» является «серьёзным предназначением, возложенным на партию историей и эпохой» ${ }^{9}$. С этой идеей на съезде были связаны практически все прошлые, настоящие и будущие начинания партии - совершение «исторических шагов», средняя зажиточность (сяокан) и, разумеется, важная идея «трех представительств» ${ }^{10}$.

Итак, в политическом лексиконе Китая прочно утвердилась единая формулировка: «великое возрождение нации Китая». В целях лучшего понимания этого лозунга разумно, как представляется, попытаться разобраться отдельно с тем, какой смысл вкладывается в словосочетания «великое возрождение» и «нация Китая».

«Нация Китая» (чжунхуа миньцзу) - понятие, впервые введенное в политический оборот «отцом нации» Сунь Ятсеном. Оно изначально обозначало национальное и одновременно политическое образование, призванное объединить народы Китая, Монголии, Тибета, Синьцзяна. Сунь Ятсен писал: «Во времена расцвета бывшей цинской династии были аннексированы Монголия, Тибет, Цинхай и Синьзян-Хуэйская область. Присоединение этой огромной территории к государству Восточной Азии было в интересах одного только императора и ни в малейшей степени не в интересах народа»"1. «Теперь, когда в нашей стране установлена республика, наши сограждане из Монголии, Тибета, Цинхая и Синьцзн-Хуэйской области, которые раньше были угнетенными народами, стали хозяевами республики. Они теперь имеют право участвовать в управлении государством» ${ }^{12}$.

Первоначально он думал о создании государства пяти наций, но вскоре от этой идеи отказался. Китай должен стать государством одной нации. Так появилось понятие «нация Китая» (чжунхуа миньцзу). По предложению Сунь Ятсена в Декларацию III съезда Гоминьдана было включено требование «сплотить 400-миллионный народ в одну государственную нацию» ${ }^{13}$. Его идея заключалась в том, чтобы китайцы (ханьцы) объединили все свои кланы (цзунцзу) как малые объеди- 
Начия в трактовке китайского гоминьдана (конеи 20-x 30-е zоды). - Перспективы сотрудничества Китая, России и других cmpan Северо-Восточной Азии в коние $X X-$ начале $X X I$ века. Тезисы докладов VIII Международпой паучной копференции "Китай, Китайская цивитизачия и мир. История, современиость, перспективы) (Москва, 7-9 октября 1997 2.). Yacmb 2. -

M.: Hucmumy'm Дальнего Востока PAH, 1997. - C. 43; Москалев А.А. Нациолализм Сунь сена в изложении Ван Цзинвэя. - Проб.лемtbl и потенциал устойчивого развиmuя Китая и России в XXIвеке. Тезисы докиадов VII Mеждународной научной конференции "Киmaй, Kuтайская чивитизация и мир. История, современность, nepcnekmuвы) (Москва, 25-27 сентября 1996 г.). Yacmib 2. - M. Hucmuтум Дальнеzо Bостока PAH, 1996. - C. 34-37.

" Ma Weigang, Ma Weijie. Guangrong yiu mengxiang.

Zhonguo: xia yige ushi nian (Cлава $u$ мечmы. Kuтай в следугшие 50 лет/ Ма Вейган и $\mathrm{Ma}$ Bейцзе). - Haikou Nanhai chubanshe, 2000. - E 72-79

is Дэи Cяопин. Llum nроизведение. C. 339

'6 Taи же, C. 358 нения (туаньти) в одно большое объединение (да туаньти) государственной нации. В Декларации V съезда Гоминьдана была поставлена задача «укреплять государственную нацию (гоцзу) и добиваться ее единства». Идея «гоцзу», по сути, отличалась от «чжунхуа минцзу» только тем, что возводила в политическую норму идею нации-государства, предусматриваюшую ассимиляцию всех неханьских народов и концентрацию политической власти в руках нации-государства.

Идея «нации Китая» оказалась поразительно живучей. Её унаследовали Чан Кайши, Мао Цзэдун. Она вошла в идейно-политический арсенал «третьего поколения китайских руководителей» и перешла по наследству «четвертому поколению».

Мало сказать, что на XVI съезде Компартии Китая был сделан важный шаг по пути эластичной подмены социальной идеи национальной. Принципиально важно, что идее «великого возрождения нации Китая» придан новый смысл, новое направление и новая форма реализации. В сводном виде она воплощена в глобальной стратегии внешнеэкономического наступления, получившей известность под девизом «Идти вовне».

Цель стратегии, как явствует из многочисленных китайских публикаций до съезда ${ }^{14}$, - превратить КНР к 2020-2030 гг. в самую экономически мощную державу мира. На XVI съезде КПК цель новой стратегии не оглашалась. Была, однако, поставлена задача - увеличить к 2020 г. объём ВВП в 4 раза. Именно такой рост, по расчётам китайских плановиков, необходим, что обойти СШША. При анализе идейнополитической платформы партии не имеет значения, сколь реальна поставленная цель и достаточен ли предусмотренный рост экономического потенциала для того, чтобы Китай действительно превратился в самую экономически мощную державу мира. Это темы иного плана. Важно, что мечта об экономическом возвышении Китая всегда согревала патриотов. Дэн Сяопин в 1988 г. говорил в беседе с премьером Радживом Ганди: «Пока Китай и Индия остаются неразвитыми, не может быть и речи об азиатском веке. Настоящий азиатско-тихоокеанский или азиатский век наступит только тогда, когда Китай, Индия и соседние с ними страны достигнут должного уровня развития» ${ }^{15}$. Дэн Сяопин считал, что такого развития Китай сможет добиться к 2050 г. или несколько позже. На XVI съезде сроки сокрашены более чем в 2 раза.

Подготовка стратегии началась в начале 1990-х годов. 16 июня 1989 г. в беседе с ответственными работниками ЦК КПК Дэн Сяопин говорил: «Я предлагаю создать группу, которая займется изучением проблем стратегии и программой развития на первую половину грядущего века... ${ }^{16}$ Такая работа была проведена. В 1997 г. на XV съезде КПК говорилось о необходимости активной внешнеэкономической деятельности и, в частности, о создании крупных китайских транснациональных корпораций, глобальной многосторонней торговой сис- 
${ }_{17}$ Zhongguo gungchandag di shiu ci quinguo daibiaodahoi wenjian hoipian (Cóopruk докулнентв XV Bсекитайского съезда Конитистической партии Китая). -

Beijing: Renmin chubanshe, 1997. E 23, 29-30.

18 "Zou chuqu» kaifang zhanlue yiu anle yanjiu / Li Gang shupianthe (Изучеuиe omкрыmой стратегии "Идти вовне» и её ироектов / nод редакиией Ли Tana). - Beijing: Zhongguo duiwai jingji maoyi chubanshe, 2000. E9

${ }^{19} 2000$ nian Zhongguo jingil quinjing / Li Jingwen

zhupian (Полная картина эконюмики Китая в 2000 г. / Га. ред. Ли Цзильень ). -

Beijing: Tuanjie chubanshe, 1999. E 350 . темы, вывозе капитала, использовании «двух рынков», «двух источников сырья» (внутренних и зарубежных) ${ }^{17}$. Все эти положения через три года вошли в состав ведущих конструкций стратегии глобального внешнеэкономического наступления. На XV съезде, однако, ешё не было речи о новой стратегии. За годы, прошедшие с тех пор, были проанализированы многие вопросы мировой политики и экономики, выявлено, как утверждается в китайской печати, главное внешнеэкономическое «сравнительное преимущество» Китая - гигантские ресурсы дешевой рабочей силы. Именно с учётом максимального использования этого «преимущества» и была разработана стратегия «Идти вовне».

По сути дела, без публичного обсуждения на XVI съезде были изменены и цели, и сроки, и содержание «третьего исторического шага». Идея Дэн Сяопина пересмотрена и её сушество принципиально изменено. «Два удвоения» предложено осуществить не за 50 , а за 20 лет. Вместо достижения среднемирового уровня благосостояния поставлена иная задача - завоевание первого места в мировой экономике. Более того, предложено отодвинуть достижение уровня средней зажиточности с 2000 г., намеченного Дэн Сяопином, а затем и партией-государством, до 2020 г. Все эти перемены подчинены «великому возрождению нации Китая».

Судя по китайским публикациям, Цзян Цзэминь назвал осуществление стратегии глобального внешнеэкономического наступления «главным полем битвы». По его словам: «Только смело и активно «идти вовне». Во-первых, только так можно восполнить недостаток национальных природных ресурсов и рынка. Во-вторых, только так можно вывозить технику, оборудование, продукцию, только так можно ещё более эффективно ввозить более новую технику, развивать новые отрасли. В-третьих, только так можно постепенно формировать наши собствениые транснациональные корпорации, чтобы ещё лучше участвовать в глобальной конкуренции. В-четвертых, только так можно ещё успешнее способ́ствовать экономическому развитию третьего мира, повышать мошь борьбы с гегемонизмом, защищать международные силы мира во всём мире» ${ }^{18}$.

В основу внешнеэкономической стратегии положены, в частности, расчеты китайских специалистов, согласно которым за 1979-1997 Гг. рост экспорта позволил обеспечить не менее $21 \%$ роста ВВП. В эти годы среднегодовые темпы прироста ВВП составили, по официальным данным, 9,8\%, из них 2,06\% были созданы благодаря наращиванию экспорта ${ }^{19}$. В условиях глубокой дефляции, определяющей внутреннюю экономическую ситуацию в стране в 1997-2002 гг., значение экспортной ориентации народного хозяйства КНР приобрело особенно большое значение. Тем более, что экономика страны стала всё острее испытывать недостаток сырьевых ресурсов, обостренный дефицитом пахотных плонадей, пресной воды, целого ряда других природных ресурсов. 
Называя реальные проблемы, требующие своего решения, Цзян Цзэминь никак не прояснил вопрос принципиальной важности: каким образом декларация о мирном наступлении сочетается с «борьбой против гегемонизма», определяющей оборотную сторону политики сотрудничества с США. После американской трагедии 11 сентября 2001 г. КНР вошла в антитеррористическую коалицию во главе с США, но программная установка о «борьбе против гегемонизма» осталась незыблемой. Новый «великий поход» во имя создания самой мощной экономической державы мира задумано осуществить под флагом «великого возрождения нации Китая» и отмщения за почти 100 -летнее её унижение со стороны империалистических государств, в том числе России. Объективно такая позиция предопределяет участие КНР в глобальных экономических отношениях в качестве антагониста США и других развитых стран мира.

Идея завоевания экономического превосходства над странами, некогда участвовавшими в унижении и грабеже Китая, призвана сплотить все классы и группы населения страны, объединить китайцев во всем мире. В ходе проведения одного исследования мои студенты и я опросили более 30 китайцев, живущих в Москве, пытаясь выяснить, что они вкладывают в понятие «нация Китая» (чжунхуа миньцзу). Мы получили два ответа. Одни считают, что «чжунхуа миньцзу» - это все жители КНР, другие думают иначе - это китайцы всего мира. Поскольку официального разъяснения встретить пока не удалось, примем эти обе точки зрения. Заметим только, что Комитет по делам зарубежных китайцев при Госсовете КНР и Ассоциация зарубежных китайцев явно интенсифицировали свою деятельность и стали активно призывать зарубежных китайцев внести новый вклад в развитие КНР и «великое возрождение нации Китая». Реализация нового «великого похода» должна, по замыслу вдохновителей, в конечном счёте, доказать всему миру подлинное велнчие, несравненное превосходство и гигантский потенциал «нации Китая». XXI век давно называют в Пекине «веком Китая».

У Китая, однако, есть немало других острейших проблем развития, которые невозможно решить на путях глобального внешнеэкономического наступления. Если вдуматься в смысл полемики, идущей в научной и общественно-политической печати вокруг перспектив страны, то можно заметить существование двух основных лагерей. Один из них образуют представители идей «великого возрождения нации Китая». Часть из них скатилась на позиции агрессивного национализма и шовинизма. Другой лагерь состоит из сторонников различных концепций «самоусиления страны». Воспитанные на традиционных доктринах «самоусиления» и «самососредоточенности», они исходят из тoro, что Китай в своём развитии столкнулся со сложнейшим комплексом проблем и противоречий, не имеющих аналогов в мире. Идея «великого возрождения нации Китая» исторнчески понятна, но на путях великодержавных устремлений её осуществить невоз- 
можно. Возрождение произойдет само собой лишь в результате разработки мер комплексного решения актуальных внутренних проблем и противоречий развития и их последовательного проведения в жизнь.

Несколько китайских ученых высказали на одной из китайских научных конференций много лет тому назад важную точку зрения. Ее суть: в Китае, как и на всей планете, есть три мира. Есть первый, наиболее развитый мир. В него входят самые промышленно развитые провинции. Есть второй мир - слаборазвитые провинции. Есть третий мир - абсолютно неразвитые провинции. Действительно, трудно себе представить, как можно решить насушные проблемы развития столь крупной и столь сложной страны, как Китай, на путях борьбы за мировое экономическое первенство.

Теперь посмотрим как соотносится стратегия «Идти вовне» с реальными проблемами Китая. Чтобы можно было примерно обрисовать сложность проблем и противоречий страны, обратимся только к одному показателю - абсолютным размерам регионального внутреннего продукта (РВГ) в провинциях, городах центрального подчинения и автономных районах Китая в 2001 г. (см. диаграмму). В ней не представлены данные только по Тибету. Разрыв между провинциями остается гигантским. РВП Гуандуна, наиболее развитой провинции, в 35 раз превышает РВП Нинся-Хуэйского автономного района! С учётом Тибета разрыв будет ещё больше.

Диаграмма Региональный внутренний продукт по провинциям, городам центрального подчинения и автономным районам Китая, 2001 г.

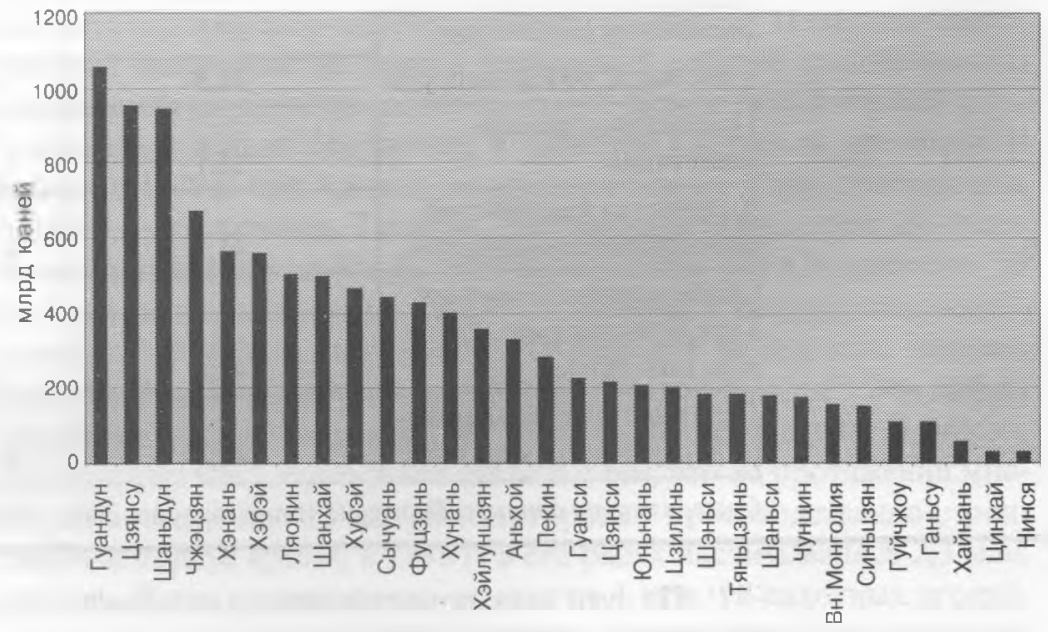

Составлена по данным: Zhongguo tongji zhaiyao, 2002 (Краткий статистический ежегодник Китая). - Beijing: Zhongguo tongji chubanshe, 2002. - E20. 
В Китае действительно сосушествуют разные миры. И нельзя сказать, что осуществление политики реформ и открытости позволило сократить разрыв между ними. Наоборот, он возрос. При провозглашении политики Дэн Сяопин и его сторонники надеялись, что опережающее развитие приморских провинций явится мощным локомотивом, обеспечивающим подъём экономики всей страны. Надеждам не суждено было сбыться. В последние несколько лет в стране развернулась кампания, направленная на развитие внутренних, главным образом западных провинций. Пока эффекта она не дала.

Приморские провинции оказались экономически более связанными с мировым, нежели с национальным рынком. Сопоставим несколько показателей, характеризующих объём международных экономических связей двух упомянутых выше групп провинций КНР.

В число наименее развитых регионов страны входит остров Хайнань, имеюший статус провинции и одновременно особого экономического района. Как и в других особых экономических районах, здесь проводится льготная политика, предусматривающцая привлечение иностранного капитала и развитие ориентированных на экспорт производств. Если исключить показатели по Хайнань, то станет ясно, что огромная часть территории страны практически не имеет сколько-нибудь заметных связей с мировой экономикой.

\begin{tabular}{|c|c|c|c|}
\hline \multirow[t]{8}{*}{ Таблица } & \multicolumn{3}{|c|}{$\begin{array}{l}\text { Некоторые показатели взаимодействия отдельных регионов КНР } \\
\text { с мировым хозяйством, } 2000 \text { г. (в процентах к итогу по стране). }\end{array}$} \\
\hline & & $\begin{array}{c}\text { Пять наиболее } \\
\text { развитьхх провинций: } \\
\text { Гуандуи, Цзянсу, } \\
\text { Чжэџзян, Шаньдун, } \\
\text { Хэнань }\end{array}$ & $\begin{array}{c}\text { Пять наименее } \\
\text { развитьхх провинций. } \\
\text { Хайлань, Гуйчжсоу, } \\
\text { Ганьсу, Цинхай, } \\
\text { Нинся }\end{array}$ \\
\hline & \multirow{2}{*}{$\begin{array}{l}\text { Внешнеторговый оборот } \\
\text { в том числе: объём экспорта }\end{array}$} & 57,1 & $0,7($ Хайнань $-0,3)$ \\
\hline & & 61,9 & $0,8($ Хайнань $-0,3)$ \\
\hline & $\begin{array}{l}\text { Прямые иностранные } \\
\text { инвестиции }\end{array}$ & 56,1 & 1,4 (Хайнань - 1,1) \\
\hline & $\begin{array}{l}\text { Количество предприятий } \\
\text { с иностранным капиталом }\end{array}$ & 45,9 & 4,5 (Хайнань - 3,6) \\
\hline & $\begin{array}{l}\text { Объём капиталовложений } \\
\text { в предприятия с иностран- } \\
\text { ным капиталом }\end{array}$ & 43,6 & 3,5 (Хайнань $-2,8)$ \\
\hline & $\begin{array}{l}\text { Доля иностранного партне- } \\
\text { ра в их уставном капитале }\end{array}$ & 45,8 & 4,0 (Хайнань - 3,3) \\
\hline
\end{tabular}

Составлена по данным: Zhongguo tongji nianjian, 2001. - E 599, 607, 610.

По сути дела, провозглашение политики, рассчитанной на формирование в КНР ориентированной на экспорт экономики, а затем стратегии глобального внешнеэкономического наступления, отража- 
ет интересы приморских, наиболее экономически развитых регионов страны. Развитие внутренних районов и внутреннего рынка оказалось малопривлекательным делом, требующим гигантских капиталовложений со слишком длительными сроками окупаемости.

Большое значение для перехода к стратегии «Идти вовне» имела ещё одна фундаментальная социально-экономическая особенность КНР - её рентный характер. Страна развивается в большой, а то и в решаюшей степени за счёт внешнеторговой ренты, создаваемой дешевой рабочей силой. Она реализуется во внешней торговле и присваивается государством и фирмами с участием иностранного капитала, то есть в преобладающей своей массе зарубежными китайскими предпринимателями. В 2000-2002 гг. во внешнюю торговлю власти КНР стали понемногу допускать национальный частный капитал. Закономерно, что именно после 2000 г. в Китае развернулись многочисленные мероприятия по более активному привлечению предпринимателей китайской ойкумены к реализации глобального внешнеэкономического наступления. Так, 28 февраля 2003 г. член Постоянного комитета Политбюро ЦК КПК Цзя Цинлинь во время приёма 62 видных представителей зарубежных китайцев отметил, что они являются важной силой, способствуюшей «великому возрождению нации Китая» и призвал десятки миллионов зарубежных китайцев впредь крепить связи с родиной, развивать сотрудничество, помогать её социаnews.xinhuanet.com $n$.../ content 751.701.ht

"Xinjiang sishi nian. 1955-1995/ qunghe quian (40 nem Cuнbизяну). - Beijing. Zhongguo tungit chubanshe, 1995. -

E 484 .

22 там же.

${ }^{23}$ Zhongguo tungji nianjian, 2002

(Статистический ежегодник Китая, 2002). - Beijing: Zhongguo tungji chubanshe, 2002. E 94, 97. листической модернизации ${ }^{20}$. Иначе говоря, новая стратегия как бы «зажигает» зелёный свет перед китайским капиталом всех стран мира, ориентируя его на полное использование «сравнительного преимушества Китая», и призывает китайцев к новому «великому походу».

Возникает вопрос: какова судьба многочисленных неханьских народов Китая. Не означает ли провозглашение «великого возрождения нации Китая» активизацию ассимиляторской политики в отношении всех национально-этнических групп населения? Политика национальной автономии не просто перекроила районы традиционного проживания народов, но изменила самую суть их политической и национальной жизни. Например, в Синцзян-Уйгурском автономном районе в 1949 г. при 4,3 млн. населения на долю уйгур приходилось почти 3,3 млн. человек. Тогда в СУАР насчитывалось всего 291 тысяча китайцев (ханьцев $)^{21}$. К 1994 г. население СУАР возросло до 16,3 млн. человек. Из них почти 7,7 млн. составили уйгуры, но 6,6 млн. китайцы $^{22}$. К 2000 г. население СУАР возросло до 18,8 млн. человек, при общей численности уйгуров во всей стране в 8,3 млн $^{23}$. Эти цифры отражают только малую толику перемен, произошедших в районе. Главная перемена неразрывно связана с тем, что на протяжении многих десятилетий в СУАР расквартирован производственно-строительный корпус армии, в 1998 г. в его рядах насчитывалось 2,3 млн. человек. В его распоряжении находятся 1 млн. га пахотных угодий, 2,8 млн. га природных и искусственных пастбищ. В его составе насчитывается более 5000 предприятий. Корпус «сыграл и играет особую 
${ }^{24}$ O Kumae, № 284. Производственностроительный корпус в Синьизяне. -

Пекин, Редакчия иллюстрированного журнала "Китай", 1998. роль в экономическом строительстве, в укреплении единства государства и национальной сплоченности. Оазисы, созданные корпусом на протяжении многих лет, образуют два гигантских кольца, окруженных пустынями Такла-Макан и Тунгут, они славятся как Зеленая стена на Северо-Западе Китая... Предприятия корпуса образовали сравнительно целостную систему хозяйства и общественного развития. Корпус по-настоящему осуществил интеграцию сельского хозяйства, промышленности и торговли, в 1990 г. китайское правительство решило дополнительно разработать специальный план по развитию деятельности корпуса» ${ }^{24}$. В свете сказанного трудно умалить роль корпуса в «великом возрождении нации Китая».

Возникает, однако, немало вопросов, на которые в Пекине предпочитают не давать ответов. Например, тибетцы, представители особой мировой цивилизации, являются, согласно сложившимся в Китае представлениям, частью единой нации - «чжунхуа миньцзу». Уйгуры. казахи, монголы, тувинцы и многие другие национально-этнические образования - также часть этой единой нации? Как в Китае мыслится обойтись с теми неханьскими этносами, часть которых жнвет на территории Китая, но часть исторически жила и продолжает жить вне пределов этой страны? Некоторые из них располагают национальными государствами. Им также уготована судьба безусловного вхождения в КНР в соответствии с принципом «одна страна - две системы», то есть безусловного слияния в едином государстве? Приходится учитывать, что в Пекине официально отвергнут принцип федерализма.

Итак, в КНР, похоже, разворачиваются совершенно новые процессы, способные в корне изменить не только сам Китай, но и существенно повлиять на окружающий мир. Может быть, лозунг «великого возрождения нации Китая» встретит определенный положительный отклик, особенно в его экономической части, у обширной китайской ойкумены за пределами Китая, у китайской национальной буржуазии, неразрывно связанной с государственной властью и выросшей на государственном капитале. Государство, однако, не сможет консолидировать многонациональный народ на путях изнурительной борьбы за первенство на мировой экономической арене. Она неизбежно будет сопровождаться углублением и обострением внутренних проблем и противоречий, а одновременно усложнением национальных условий жизни отдельных национально-этнических групп населения и противопоставлением их интересов. 